\title{
PROCEDURAL OPTIONS FOR MEASURING MUSCLE STRENGTH
}

\author{
S. Mindova, I. Karaganova and I. Stefanova \\ Faculty of Public Health and Health Care, University of Ruse "Angel Kanchev", Ruse, Bulgaria
}

\begin{abstract}
Summary. The aim of the present study was to provide alternative means of measurement and evaluation of muscle strength in rehabilitation practice and diagnostics. In the last few years many electronic devices for evaluation of muscle strength have developed. Contemporary studies have shown that in addition to the standard manual muscle testing muscle strength can be assessed more objectively and analytically using electronic dynamometers and equipment. The strain gauges are used as a tool of precision in the industry that allows measurement of mechanical loads by dynamometers. By using these tools is possible to obtain continuous digital measurement and recording of muscle strength.
\end{abstract}

Key words: muscle strength, measurement of muscle strength, dynamometers, handheld dynamometry, muscle testing

\section{INTRODUCTION}

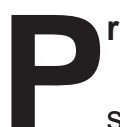
rocedural options for measuring muscle strength

There are numerous procedural options for measuring muscle strength. The measurement of muscle strength is clearly an important component of the physical therapists' examination of patients with neurological disorders.

Functional assessment according to international system of functional status (ICE) is an important component for categorization of disability and dysfunction, for the implementation of appropriate therapy planning and forecasting of the state [7].

Muscle testing is a basic tool of applied kinesiology, which evaluates the adaptation of the muscle subjected to variable force. In kinesiology it is art the precise use of the test as a tool that can provide the information necessary for the action of the muscles in the kinetic chain or define the problem, its level, and the way in which it can be influenced [11]. 


\section{AIM OF THE STUDY}

To overcome the limitations of the manual muscle testing (MMT), dynamometers have been developed to aid therapists in clinics. With our research we aimed to acquaint the audience with the types of dynamometers, we classified them in several groups according to the type and application.

Dynamometers or force measuring devices can be categorized as: hand-grip dynamometers, hand-held dynamometers, fixed dynamometers, and isokinetic dynamometers. Each provides a quantitative indication of the force or the torque, thus individuals are able to bring to bear on the environment under specific conditions [8].

Hand-grip Dynamometry

Hand-grip dynamometry (HGD) refers to the measurement of hand strength with a dynamometer. Hand-grip dynamometry has been used extensively with neurologic patients. The America Society of Hand Therapists recommends use of the Jamar dynamometer in the second handle position [2], but other instruments have been employed such as MicroFET4 dynamometer (Fig. 1). The Society also recommends the tested individual to be seated with the shoulder adducted (arm against side) and the elbow at 90 degrees [5].

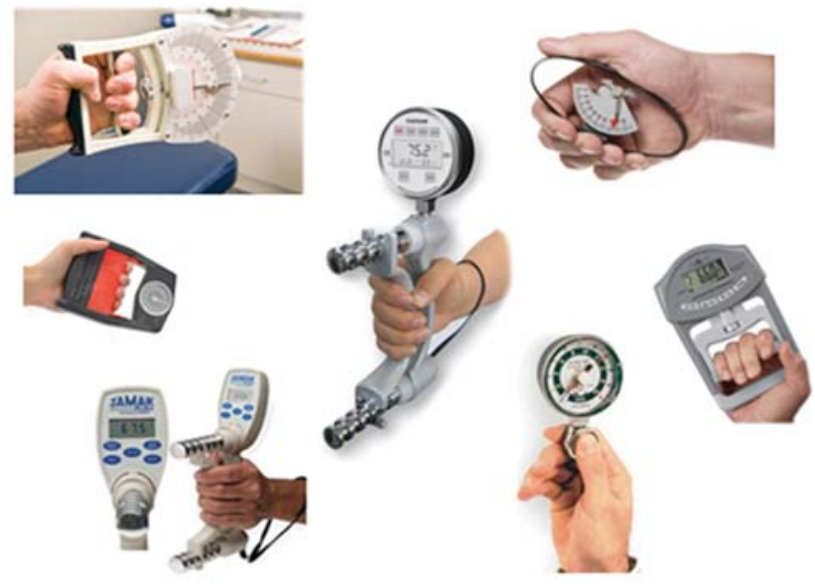

Fig. 1. Hand-grip Dynamometry

\section{Hand-held Dynamometry}

The term hand-held dynamometry (HHD), unlike the hand-grip dynamometry, refers to the measurement of muscle strength using a device held in the hand of the examiner (Fig. 2). Hand-held dynamometry can be used in a make test mode or a break test mode. 

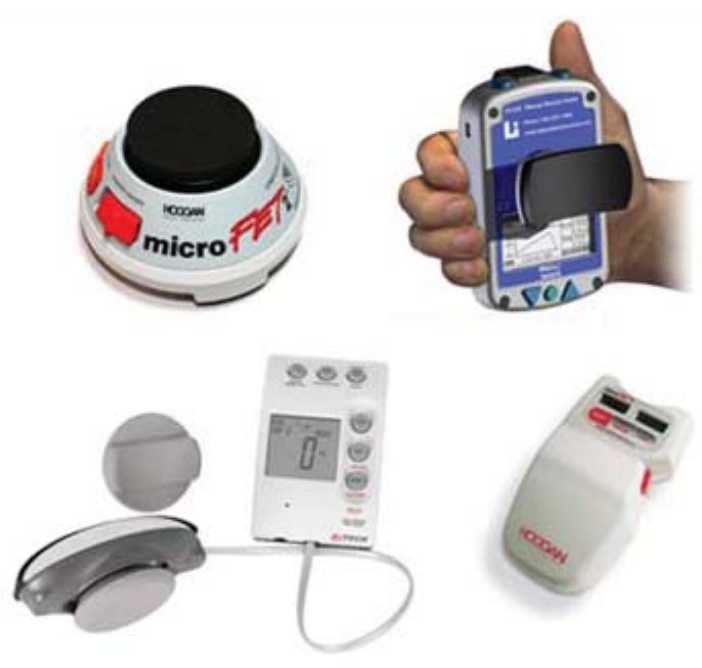

Fig. 2. Hand-held Dynamometry

They are designed for high durability and reproducibility of the data. They have their own graphic display, easily replaceable comfortable stirrups with pads, interactive menus allowing selection of different options automatically or manually store up to 150 test opportunities to review stored data. They can eliminate errors due to non-perpendicular position of the limb [10;8].

Ergonomic design, size and weight of the device allow the use of procedures, starting points and test techniques described in the literature and taught in academia.

Resistance applied by testing to the limb through. HHD are easily applicable to the study of more than 15 muscle actions of the limbs and trunk. Tested muscles should have the possibility to move against gravity [12].

Fixed Dynamometry

Fixed dynamometry (Fig. 3) refers to the isometric measurement of muscle strength using a dynamometer fixed via a frame or some other stable structure.

Though used most often for testing muscle force at the knee, frames have been developed for measuring multiple muscle actions in patients with neurologic conditions such as amyotrophic lateral sclerosis.

Hand-held dynamometers have been fixed rigidly or stabilized via straps in several studies. While removing the issue of tester strength from the results obtained, fixation also adds to the time required to test multiple muscle actions. Compared with fixed isokinetic dynamometer (IKD), MMT and manual dynamometers (HHD), fixed dynamometers have greater "flexibility" of the application and can be used to assess the maximum force [6]. 


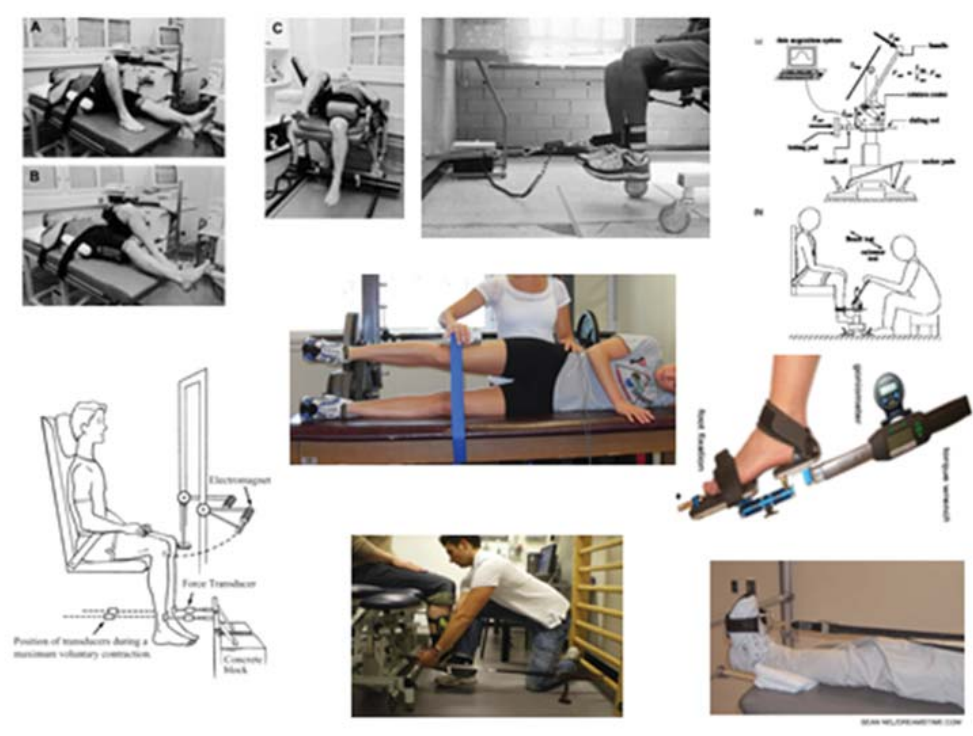

Fig. 3. Fixed Dynamometry

According to Escolar et al. fixed dynamometry is more reliable than MMT and requires less training to achieve an acceptable level of reliability [4]. The convergent validity of fixed dynamometry is evinced by moderate to strong correlations between strength measures obtained with fixed dynamometry and manual muscle testing and hand-held dynamometry. Fixed dynamometry is responsive to changes in muscle strength. It has been used to document the dramatic deterioration in muscle strength associated with amyotrophic lateral sclerosis [1].

Isokinetic Dynamometry

Isokinetic dynamometry, probably better referred to as isokinetic dynamometry, refers to the measurement of muscle strength or other performance parameters with a device that is able to control angular or linear speed during testing (Fig. 4). Isokinetic dynamometers are capable of and sometimes used to measure isometric strength.

Isokinetic dynamometers are capable to measure the isometric force. In these types of dynamometers it is not possible to test more movements and to eliminate gravity, but on the possible adjustment of gravity, which is especially important for patients with muscle weakness [9]. Reliability of isokinetic dynamometers in individuals with neurological diseases has received considerable attention [3]. 


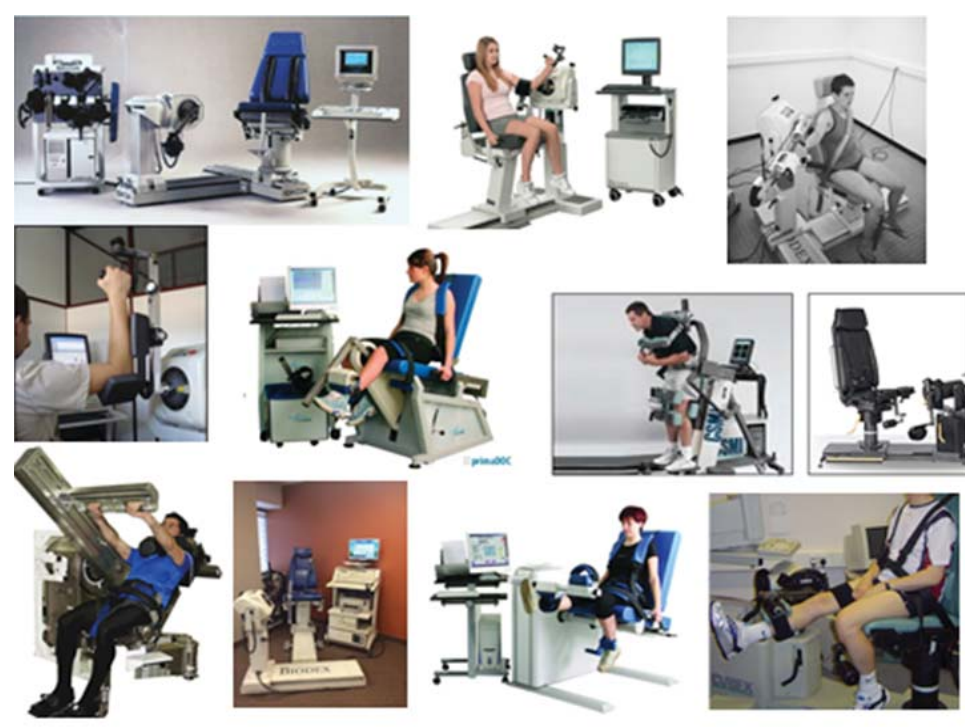

Fig. 4. Isokinetic Dynamometry

Van den Berg-Emons, van Baak, de Barbanson, and others reported that the reliability coefficients are acceptable and some of them are very high. More difficult is to obtain reliable measures at higher angular velocities, revealing a convergent validity between isokinetic dynamometers, MMT and manual dynamometers [9].

Not all of the options for testing the strength are equally practical. Since it does not include equipment, MMT has a clear advantage in terms of portability and cost. HGD are transported comfortably and are not too expensive. However, they are not easily adapted to measure the actions in hand other than grip. HHD are easily transportable and generally more expensive than dynamometers HGD, but are easily applicable to the study of more than 15 muscle actions of the limbs and trunk.

\section{REFERENCES}

1. Andres, PL., Skerry LM, Thorneli B., et al., A comparison of three measures of disease progression in ALS. J Neurol Sci, 1996.

2. Bohannon, R. Measuring muscle strength in neurological disorders. Fyzyoter Rehabil, 2005.

3. Eng JJ., Kim CM, Maclntyre DL., Reliability of lower extremity strength measures in persons with chronic stroke. Arch Phys Med Rehabil., 2002.

4. Escolar, DM. Henricson EK, Mayhew J, et al., Clinical evaluator reliability for quantitative and manual muscle testing measures of strength in children. Muscle Nerv, 2001.

5. Fess, EE. Grip strength. In: Casanova JS, ed. Clinical assessment recommendations.2nd ed. Chicago: American Society of Hand Therapists, 1992.

6. Fransen, M., Crosbie J, Edmonds J. Isometric muscle force measurement for clinicians treating patients with osteoarthritis of knee. Arthritis Rheum, 2003 
7. Popov, N., Funkcionalno izsledvane i analiz v muskulno-skeletnata fizioterapia, S., 2012.

8. Schmitt, WH., Cuthbert SC., Common errors and clinical guidelines for manual muscle testing: "The arm test" and other inaccurate procedures. Chiropractic \& Osteopathy 2008; $16: 16$ doi: 10.1186/1746-1340:16-16

9. Tiffreau, V., A. Turlure, G. Viet, et al., Isokinetic dynamometry of weak muscles. Isokinet Exer Sci, 2003.

10. www. lafayetteinstrument.com

11. www. nice-kinesiologie.com

12. www. rehabmeasures.org

Corresponding author:

Stefka Pavlova Mindova, Assoc. Prof.

Faculty of Public Health and Health Care

University of Ruse "Angel Kanchev"

97 "Alexandrovska" str.

$\mathrm{Bg}-7000$ Ruse

e-mail: smindova@uni-ruse.bg 